\title{
Impact of Climate Change on Animal Production and Expansion of Animal Disease: A Review on Ethiopia Perspective
}

\section{Wakgari Abirham Haile*}

College of Veterinary Medicine and Animal Production, University of Gondar, Gondar, Ethiopia.

*Correspondence: bashirabirham@gmail.com

\begin{abstract}
Climate change is a result of the global increase in average air and ocean temperatures, and rising average sea levels. Livestock production and health are significantly vulnerable to the impact of climate change. Climate change has direct and indirect impacts on emerging and re-emerging animal diseases and zoonoses since it disrupts natural ecosystems and allows disease-causing pathogens to move into new areas where they may harm wild life and domestic species, as well as humans. Climate change affects diseases and pest distributions, range prevalence, incidence and seasonality but the degree of change remains highly uncertain. The occurrence and distribution of vector borne diseases such as bluetongue, west nile fever, rift valley fever, African horse sickness, etc. are closely associated with weather patterns and long-term climatic factors strongly influence the incidence of outbreaks. The interaction between animal production and climate change is complex and multidirectional since animal production contributes to climate change; but to the reverse and more worse condition, climate change highly affects animal production. Climate change, animal production systems and animal diseases are strongly linked each other. But what is worse is that both change in climate and the production systems of animals highly affect the occurrence, distribution, emergence and reemergence of animal diseases. The close linkage among climate change, animal production and disease; the increased threat of climate on the animal production and health sectors needs: the hands of stakeholders in the environment, animal production and health to work in an integrated and systematic manner; researches with emphasis given to the state of climate change and the direct and indirect effects it pose on animal production and health; and ensuring development of sustainable animal farming and land use, and climate adaptation and mitigation strategies.
\end{abstract}

Keywords: Climate change, Animal production, Animal diseases, Animal health, Expansion, and Impact.

\section{INTRODUCTION}

Climate change is a result of the global increase in average air and ocean temperatures, and rising average sea levels and has become the main issue affecting global and regional natural eco-systems (IPCC, 2007). The world's climate was reported to be warming at a faster rate than ever before (IPCC, 2007), with concomitant changes in precipitation, flooding, winds and the frequency of extreme events such as El Niño. The average temperature in the world has increased in the last few years compared to the previous century and is expected to continue rising if measures are not taken particularly by highly industrialized countries to reduce greenhouse gases emissions (IAEA, 2017). 
Though Changes in climate and extreme weather events have received increased attention in the recent years, climate change is real and is happening now. It will become worse in future with more impacts to rural poor communities of developing countries (Kimaro and Chibinga, 2013).

Agriculture and livestock are amongst the most climate sensitive economic sectors in the developing countries. Livestock production and health are significantly vulnerable to the impact of climate change (Kimaro and Chibinga, 2013). Climate change has negative effects on livestock health in many aspects and can exacerbate disease in livestock and some diseases are especially sensitive to climate change (Nejash and Kula, 2016; Shahen et al., 2019). Based on IPCC (2007) report, global changes in temperature may affect the incidence and range of several infectious diseases within endemic areas and their introduction to free areas (Hansen et al., 2005). Approximately 80\% of emerging infectious diseases affecting humans and a rising number of these diseases (example severe acute respiratory syndrome (SARS), monkey pox, Marburg diseases and Ebola) are spread by contact with wildlife. A report by IAEA (2017) indicated that the most important immediate consequences of global warming would be an increased incidence in deadly infectious diseases in wildlife, livestock, and people. These emerging diseases can have serious consequences for public health, the economy and species conservation (Md et al., 2014). For instance SARS alone has killed over 700 people and has cost the global economy US\$ 50 billion. When such diseases appear and spread unabated, confidence in the structure of civil society designed to protect life and conserve natural resources will be eroded ( $\mathrm{Li}$ et al., 2005).

Vector borne diseases are particularly affected by weather patterns and long-term climatic factors strongly influence the incidence of outbreaks (Rahman et al., 2019). Most of these diseases are caused by insects and their population dynamics is dependent on the prevailing weather conditions, specifically temperature and humidity (IAEA, 2017). Because arthropods are highly sensitive to environmental and seasonal temperatures, the range of vector-borne diseases such as bluetongue, west Nile fever, Venezuelan equine encephalitis, rift valley fever, African horse sickness and visceral leishmaniasis may be limited or exacerbated by the distribution of competent vectors (Purse et al., 2005). The rapid spread of the above mentioned diseases has been driven by climate change. In addition, animal parasites including tick- borne diseases in Africa and New world screwworm (Cochliomyia hominivorax) in south America had been reported to spread to new regions, causing negative impact on livestock production and causing direct and/or indirect effects on public health (Rappole et al., 2000).

Though the links between animal production and climate change are complex and multi-directional, climate change influences livestock production by affecting the conditions governing animal production, fodder crop production and animal health (Walter et al., 2010). The vulnerability of animal production, warming those animal production facilities will be affected both directly and indirectly by climate change (IPCC, 2007). Although there are enormous amount of researches and scientific deals about climate change, reports regarding the impact of climate change on animal production and animal diseases including the linkage among the three are scarce. Therefore, this seminar review is geared with the objectives of: (i) organizing scientific reports about the impacts that climate change may pose on animal production and animal diseases; (ii) reviewing some concepts and reports, from different scientific deals, about the linkage among climate change, animal production and animal diseases (Abrar et al., 2020).

Climate Change and Animal Diseases - Climate change has had an unprecedented worldwide impact on emerging and re-emerging animal diseases and zoonoses. Climate change is disrupting natural ecosystems by providing more suitable environments for infectious diseases allowing disease-causing bacteria, viruses, and fungi to move into new areas where they may harm wild life and domestic species, as well as humans. There is evidence that the increasing occurrence of tropical infectious diseases in the mid latitudes is linked to global warming. Climate change influences local weather conditions and 
therefore has a significant impact on the presence of insects and their geographical distribution (IAEA, 2003-2017). Climate change has negative effects on livestock health in many aspects. It may influence livestock health through a number of factors, including the range and abundance of vectors and wildlife reservoirs, the survival of pathogens in the environment. Climate change can exacerbate disease in livestock and some diseases are especially sensitive to climate change. Indeed a better understanding of the effect of climate change on animal health is crucial and good for recommendations on how to lessen its potential impact (Nejash and Kula, 2016).

\section{Impacts of Climate Change on Animal Diseases -}

Climate change is expected to affect disease and pests distributions, range prevalence, incidence and seasonality but the degree of change remains highly uncertain. It is expected to affect both pathogen and vector habitat through changes in temperature, precipitation, humidity and wind patterns. Heat stress and drought are likely to have further negative impacts on animal and human health and disease resistance (IPCC, 2007). It has been reported that animals in the Afar regional state had suffered from the burden of endemic and varieties of newly emerged animal diseases which can be linked to the changing climate and the extreme weather conditions. Cold- blooded vectors are sensitive to direct effects of climate such as temperature, rain fall patterns and wind. Rising temperature influences the production and maturity rate of infective agents as well as the survival rate of the vector organisms, thereby further influencing disease transmission (IPCC, 2007). Climate also affects their distribution and abundance through its effects on host plants and animals.

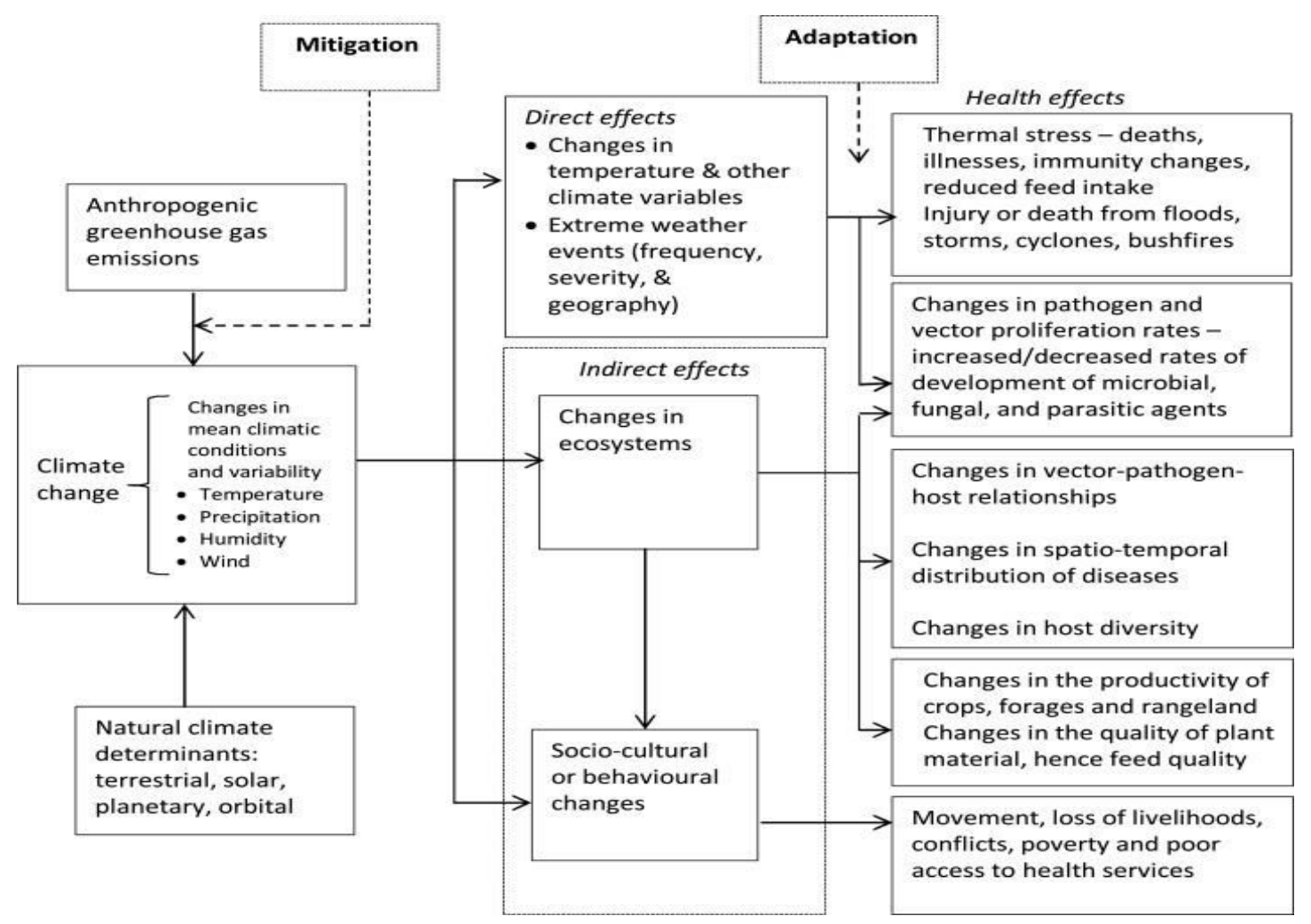

Fig 1: Illustration of the direct and indirect pathways through which climate change influences livestock diseases (Bett et al., 2016).

Climate change can have direct and indirect effects on infectious diseases. Direct effects manifest as reduced capacity of the hosts to mount a response to infection (e.g. due to heat stress) or increased development rates of pathogens and vectors. Indirect effects, on the other hand, are associated with climate-driven ecosystem changes or socio-cultural and behavioral adaptations which could also amplify vector/pathogen develop- 
ment, or increase vector-pathogen-host contact. The socio-cultural and behavioural adaptations include livelihood practices such as increased frequency and range of migration often associated with pastoral communities (Fig 1). Direct pathways include processes that affect host immunity and/or pathogen and vector development dynamics, while indirect processes include processes that destabilize disease ecology, leading to an increase or decrease of contact between vectors, pathogens and hosts, or increased persistence of pathogens in an environment (Bett et al., 2016).

It was described that landscape changes that remove portions of host populations (example habitat alteration or destruction), alteration of host migration patterns (example habitat fragmentation) and increased host density were factors that affect animal diseases emergence and re-emergence. The geographical distribution of vector-borne diseases is influenced by the geographical distribution of both vertebrate host and the distribution of the vector; other contagious diseases are also subject to a degree of environmental influences, including parasite life cycles which can be transmitted by wind-borne aerosol spread (Baylis and Githeko, 2006). Increased precipitation may also cause changes in the prevalence and intensity of parasite infestations, increasing host mortality in wild and domestic species (Daszak et al., 2003).

\section{Impact of climate change on pathogens and hosts -} Even though limited work has been done to determine the effects of temperature changes on pathogens, a rise in temperature increases replication rates of pathogens in the vector, therefore shortening their extrinsic incubation period. This suggests that within the limits when the vector survival is ideal, higher temperatures should result in shorter development interval of the virus in the vector, and hence greater chances of the vector living longer to transmit the infection. Temperature also has substantial effects on pathogens that spent part of their life cycles outside a mammalian host such as the agents that cause anthrax, black quarter and dermatophiloses, helminths, etc (Bett et al., 2016). In nature pathogens can be transmitted directly between animals or indirectly through intermediate hosts. Indirect transmission aids are often UniversePG I www.universepg.com affected by environmental conditions such as temperature and rain fall. Higher temperatures associated with climate change may contribute to an increase in pathogens with intermediate hosts and vectors or in erased survival of animals that labor disease (Kutz et al., 2005). Survival of some parasites was reported to be increased by warmer temperatures and milder winters in the north central United States and Northern Canada. Climate change would lead animals to be stressed by heat (Lenarz et al., 2009) and as result becoming more susceptible to parasitic and infectious diseases (Murray et al., 2009).

The more contact between wildlife populations and domestic species the higher the likelihood of exposure to novel pathogens, leading to emergence of new diseases in humans and animals. For example neutralizing anti-bodies against Para-influenza PI-3, a virus which is relatively common in cattle, have been found in Huemui deer in Chile (a species which is in danger extinction). For contagious animal diseases, climate may be associated with seasonal occurrence of diseases rather than with spatial propagation. These is evidence for pathogens or parasitic diseases, such as Fasciolosis, in areas with higher temperatures, when seasonality is extended as a consequence of the increased survival of the parasite outside the host or, conversely, shortened by increased summer dryness that decreases their numbers (Baylis and Githeko, 2006).

For other pathogens, such as parasites that spend part of their life cycle as free stages outside the host, temperature and humidity may affect the duration of survival. Climate change could modify the rate of development of parasites, increasing in some cases the number of generations and then extending the temporal and geographical distribution. New world screwworm infestations had been observed to increase in spring and summer and decrease in autumn and winter in South America (Madeira et al., 2005). On the other hand, Leishmaniasis in humans has been associated with the increased frequency of drought as this facilitates reproduction and growth of adult sand flies (Cardenas et al., 2006). Wild birds are known to be reservoirs for several pathogens, including west Nile virus ( WNV), and serve as amplifying hosts for the 
virus in nature (Reed et al., 2003). The migration of birds is driven in part by seasonal climatic factors, and any change in climatic conditions may modify the direction and intensity of spread of disease. Similar disease ecology and wildlife interactions of pathogens associated with birds have been observed for Newcastle diseases, WNV (Bosh et al., 2007, influenza A virus (Reed et al., 2003). The mosquitoes Culex species, example, Culex pipiens, Culex restuans play an important role as vectors, for WNV. Bluetongue virus, which is transmitted by Culicoides species, midges has been historically distributed between latitudes $40^{\circ} \mathrm{N}$ and $35^{\circ} \mathrm{S}$. Vesiculo viruses which cause vascular stomatitis can be insect-transmitted and has been isolated from species of midges (culicoides species) and hlevotomine flies, including sand flies (Lutzomyta species) and black flies (simuliidae species). An antibody to vesiculovirus has been detected in monkeys, marsupials, bats, carnivores, deer and rodents throughout America. Seasonal variation is observed in the occurrence of virus: it disappears of the end of rainy season in tropical areas and at the time of the first frosts in temperate zone (Sarkar et al., 2020).

\section{Impact of climate change on epidemiology of} animal diseases - Diseases that were previously limited only to tropical areas are now spreading to other previously cooler areas (Lowen et al., 2007). Pathogens that were restricted by seasonal weather patterns can invade new areas and find new susceptible species as the climate warms and/or the winters get milder (IAEA, 2017). The role of environmental pathogen load is perhaps more obvious still in the case of fecal-oral or water-borne transmission. Food poisoning is usually due to fecal contamination of food items. The natural cycle of Avian influenza virus in mallard ducks, it is for a most natural host, involves ingestion of water containing the virus. Natural avian influenza virus replication occurs mainly in the distal end of the enteric duck tract. Virus deposited migratory water fowl during summer breeding at higher latitudes may be stored in permafrost conditions in sub-arctic regions and survive for centuries (Zhang et al., 2006). Likewise does the anaerobe Bacillus anthrax bacterium survive for decades in the form spores in the soil?

UniversePG I www.universepg.com
Disease agents transmitted by arthropods form a distinct, albeit related category. Indirect transmission of protozoan disease agents may be facilitated by most ticks. Soft ticks feeding on warthogs play a role in the transmission of African Swine Fever (ASF) (Kleiboeker and Scoles, 2001).

The causative agent of ASF, a DNA virus, may survive for eight years in the tick vector. Some insect-borne disease can survive in dormant form. For example, Rift valley fever (RVF) virus may survive in mosquito eggs for years, until a prolonged heavy rain fall facilitates an a making of Aedes mosquitoes, feeding on ruminants and thus kick-starting a RVF outbreak. Infected ruminants that end up in densely populated irrigation schemes may also attract mosquitoes feeding on humans and thus contribute to the transmission of RVF among humans. Midges are sometimes blow by wind across wider geographic areas. These will probably what happened with bluetongue virus introduction in the United Kingdom, in the summer of 2006, after the virus had first spread west wards across Belgium (Gloster et al., 2008). It was observed that flare up of the schmallelgberg virus in the United kingdom in early 2012 resulted from wind carried infected midges arriving from main land Europe (Gibbens, 2008).

In the direct-indirect transmission spectrum, directly, swiftly transmitted common flue, short lived fevers, fecal-oral, food and vector-borne transmission to more prominent free living parasite stage can be noted. In this regard ectoparasite and myiasis causing insects may be considered. Arthropod pests are strongly modulated by climatic and weather conditions. The effect of climate change on the tsetse flies, the vector of human and animal trypanosomiasis, is rather different, deposit certain similarities between tsetse and the screwworm fly life history, the effects of climate change on disease distribution may take many different forms, compression and generalization. the tsetse fly distribution in Ethiopia entails a gradual encroachment of the country's central high and plateau, recorded since the 1960s, the old world screwworm fly colonized the Arabian peninsula, first the Mesopotamia valley in Iraq and later parts of Yemen, the course two decades (Siddig et al., 2005). 
Effects of climate change on emergence and spread of animal diseases - As global temperature increases, the effects will be quite complex and vary from region to region. Though the extent of these effects is uncertain, it is known that those communities and regions with least resources, such as rural agricultural areas will be the most vulnerable to climate change (Steinfeld et al., 2006). Warmer and wetter (particularly warmer winters) will increase the risk and occurrence of animal diseases, as certain species that serve as disease vectors, such as biting flies and ticks, are more likely to survive year round. Certain existing parasitic diseases may also become more prevalent, or their geographical range may spread, if rain fall increases. This may contribute to an increase in disease spread, including zoonotic diseases (Epstein et al., 2005). Transportation of animals for personal, entertainment, or agricultural purposes also increases possibility for the introduction and subsequent presence of diseases and pests, including ticks and parasites, previously considered exotic. The viral infection bluetongue disease, for example, was once only a threat in Africa, now affects cattle and sheep in the whole of Europe (IPCC, 2007).

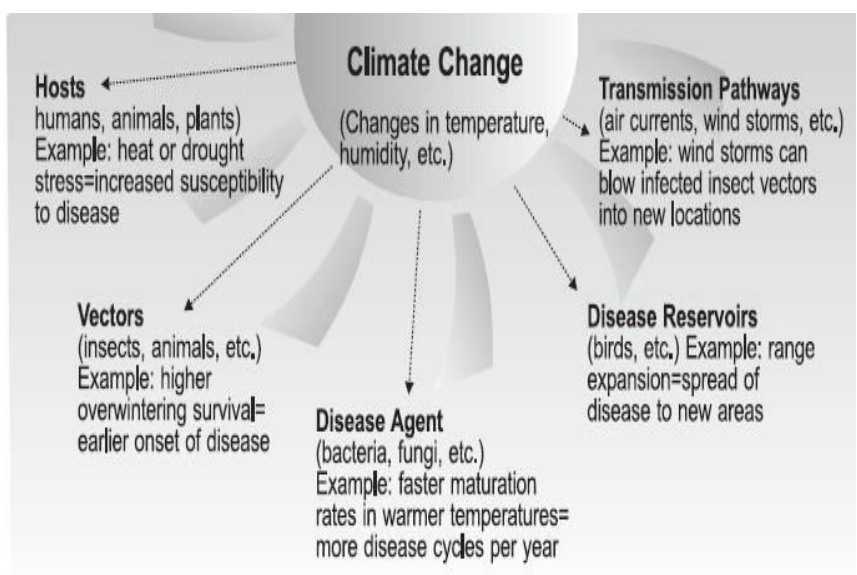

Fig 2: Identification and prediction of animal diseases due to climatic change (Greinfenhagen and Noland, 2003).

The relationship between climate change and the animal disease shown by the arrow labeled 1 in figure to describe their relation. The climate change responses are broadly consistent with other works that has highlighted the increase in the incidence of vector borne diseases in association with climate change. This increase is due to both the markedly altered vector population size and dynamics, and the increases in pathogen replication rates that are influenced directly by ambient temperatures during infection of the poikilothermic arthropod vectors (Relman et al., 2008).

Impact of climate change on vectors of animal diseases - One consequence of significant and permanent changes to our climate is the alteration of disease patterns in humans and animals. These alterations may include the emergence of new disease syndromes and a change in the prevalence of existing diseases, particularly those spread by biting insects (Purse et al., 2005). Climate change may cause vector-borne diseases to shift in distribution because the vectors' ecology and the pathogen development rate within them strongly depend on environmental conditions. In some cases, shifts to previously unexposed populations of humans and animals could have severe or even devastating consequences (Helene et al., 2011). Vectors may reach out to wider geographical areas widening their distribution patterns to non immune areas, and may recruit new vectors or new strains resulting in the spread to new hosts (Purse et al., 2005).

Insect-borne diseases are now present in temperate areas where the vector insects were nonexistent in the past e.g. trypanosomosis, anaplasmosis. Vector borne diseases are particularly affected by weather patterns and long-term climatic factors strongly influence the incidence of outbreaks. Most of these diseases are caused by insects and their population dynamics is dependent on the prevailing weather conditions, specifically temperature and humidity. It is now evident that diseases carried by insects and ticks are likely to be affected by environmental changes because these creatures are themselves very sensitive to vegetation type, temperature, humidity etc (IAEA, 2017). Predictions indicate that climate change will result in warmer temperatures and increased humidity which in turn will affect vegetation quality. These changes can influence arthropod patterns of all changes associated to climate. Warmer temperatures result in increasing vital titer with in vectors as well as vectors survival from season to season and increase in biting frequency. Therefore, increases in temperature 
can result changes in the number of vector generations and overall abundance of insect populations which in turn can influence vector population dynamics and increase transmission (De La et al., 2008). Because arthropods are highly sensitive to environmental and seasonal temperatures, the range of vector-borne diseases such as bluetongue, west Nile fever, Venezuelan equine encephalitis, rift valley fever, African horse sickness and visceral leishmaniasis may be limited by the distribution of competent vectors. For instance, the expansion of the geographical range of Anopheles vectors and the lack of well structured and financed public health systems could explain the reemergence of malaria and dengue in South America, central Africa and Asia. Similarly, some species biting midges known to be vectors for African horse sickness (AHS) and bluetongue have recently invaded Europe and North Africa (Purse et al., 2005).

There is a global trend for mosquitoes and biting midges to populate and establish themselves in new ecosystems. Although there are several historical records of bluetongue outbreaks in Europe, the recurrent exotic introductions since 1998 have been alarming, with six strains of bluetongue virus identified across 12 countries and occurring some $80 \mathrm{~km}$ further north than ever previously reported. These rapid spread has been driven by climate change, which has increased virus persistence in vector hosts during winter period and the North ward expansion of culicoides imicola, an indigenous European midge species, thereby expanding the risk of transmission over larger geographical regions. In addition, animal parasites, including tick- borne diseases in Africa and New world screwworm (Cochliomyia hominivorax) in south America, have spread to new regions, causing negative impact on livestock production and causing direct or indirect effects on public health (Rappole et al., 2000).

Understanding vector capacity is keys to understanding diseases dynamics. Many significant livestock diseases have insects (mosquitoes or ticks) as part of their transmission cycle. Bluetongue disease in cattle, ASF in pigs and Rift valley fever in ruminants are just few disease named. In humans malaria is most significant. Rainfall patterns may also have clear impact on the life cycle of pathogens and diseases. In particular the expected accumulation of water can result in nesting sites for mosquitoes to breed and expand, and as a result serve as reservoirs and transmitters for diseases. Besides changes in rainfall patterns, climate change can result in increased frequency of sever climatic event which can result an important feature of vector distribution (Abedin et al., 2020).

Impact of Climate Change on Wild life Health - The inter governmental panel on climate change projects that unprecedented rate of climate changes will result in increasing average global temperatures, rising sea levels, changing global precipitation patterns including increasing amounts and variability, and increasing mid continental summer drought. Increasing temperatures, combined with changes in rain fall and humidity, may have significant impacts on wildlife, domestic animal and human health and diseases. When combined with expanding human populations, these changes could increase demand on limited water resources, lead to more habitat destruction and provide yet more opportunities for infectious diseases to cross from one species to another (IPCC, 2007).

Climate change, habitat destruction and urbanization, the introduction exotic and invasive species and population- all affect eco-system and human health. Climate change can also be viewed within the context of other physical and climatic cycles, such as El Nino Southern oscillation (El Nino), the North Atlantic oscillation, and cycles in solar radiation that have profound effects on the earth's climate. The effects of climate change on wild life disease can be summarized in terms of geographic range and distribution of wild life diseases, plant and animal phenology, and patterns of wild life diseases, community and eco-system composition, and habitat degradation (Walter et al., 2002).

Impact on geographic range and distribution of wildlife diseases - In Northern Hemisphere, global warming has likely played a role in geographic shifts of disease vectors and parasitic diseases that have life cycles. For example the black legged tick carries and transmits Lyme disease and several other tick borne zootomic diseases in North America that has been expanding North in to Southern Ontario and Western 
Ontario and Manitoba, and more recently, into Quebec and Canada Maritime Province. In Europe, a similar North ward expansion of the European Castor bean tick, which also carries and transmits Lyme diseases, tick borne encephalitis (TBE), and other diseases, has been reported in Norway (Hasle, 2009) and Sweden. On both continents migrating birds carrying feeding ticks are likely the source of long range expansion of the tick vectors, and increasing environmental temperatures have likely permitted the tick to become established in larger geographic areas (Lindgren, 2000). Scientists also expected changes in disease distribution to occur in association with changes in latitude. For example, climate warming was reported to lead to year round transmission of mosquito borne avian malaria at higher elevations in the Hawaiian Island, further threatening enlarged native Hawaiian birds that have little or no resistance to introduced diseases. Currently on the Island of Hawaii avian malaria is limited to warmer elevations. If the higher elevations become warmer as projected, mosquito activity and parasitic development in these areas will increase. Conservationists are concerned that climate change may lead to increased avian malaria transmission throughout the year at increasing higher elevations (Nas et al., 2020).

Phenologic effects of climate change on wildlife diseases - Timing of recurring seasonal biologic cycles of some plants and animal species has already been affected by climate change (Walter et al., 2010). The timing of biological cycles, such as the arrival of a bird species in spring and the availability of its preferred food source, is critical for successful breeding and survival. Several studies in Europe show that some migratory birds have changed their migration patterns in response to climate change by arriving earlier than records show historically (Lehikoinen et al., 2004; Thorup et al., 2007). Significant population declines were reported recently for bird species that have not responded with earlier arrival, and the population declines have been interpreted as indicating the magnitude, and negative effect, in miss match between bird arrival time and the onset of plants emerging from dormancy in spring (Saino et al., 2011). Variability in the timing of biological cycles also can lead to increase or decrease in the risk for infectious diseases, particularly diseases transmitted by mosquitoes or ticks. In Europe, it was reported that transmission of TBE to humans to be increased during warmer temperatures in the early spring resulting in the overlap of feeding activity of virus infected nymphal and uninfected larval European castor bean ticks while Cooler spring temperatures resulting in less likely to pass the virus to feeding larval ticks (Randolph, 2009). In North America, the same seasonal temperature effect has been observed in the transmission of the bacterium Borella burgdorferl, cause of Lyme disease, from infected nymphal black legged ticks to uninfected larval ticks. Climate change by altering seasonal weather patterns has the potential to affect these natural cycles (Gatewood et al., 2009).

Climate Change and Animal Production - Animal production and climate change are inter-linked in complex and multi-directional ways (Walter et al., 2010). Livestock agriculture accounts for $35-40 \%$ of methane and nearly $70 \%$ of nitrous oxide worldwide, gases that rise mainly from the digestive processes of animals, and animal's waste. Levels will continue to rise as animals numbers grow to meet the increasing demands for meat and milk from developing countries. Agricultural emissions of nitrous oxide from manure and the production of artificial fertilizers are projected to increase by $35-60 \%$ by 2030 . Some developing regions will have very large increases, including parts of East Asia with an increase of 35\% from enteric fermentation and $86 \%$ for manure management.

Deforestation for animal production accounts for $85.5 \%$ of all carbon oxide life stock related emission and $34 \%$ of Carbon dioxide, methane and nitrous oxide emission. The increased production of beef in South America and Soybean production for feed transported to Europe is leading to deforestation of the rain forest, which has a great impact on the emission of GHG. Soybean production for feed also causes loses of biodiversity and chemical population (Smeraldi, 2008). On the other hand, animals are intrinsically dependent on the environment, and any fluctuation in weather and climate can affect them through water scarcity, environmental changes such as desertification, and feed and water availability, access, and appropriateness (Rafiquzzaman, 2020). Climate change will not only 
impact the health and welfare of animals, but also the more than billion people who depend on them. Desertification and climate change are inextricably linked through feed backs between land degradation and precipitation. Less rain leads to soil compaction and hardening, making the land an able to absorb rain water. These could have disastrous effects as rain become less frequent but heavier. The increased use of chemical-based agricultural inputs, including artificial fertilizers, pesticides, and herbicides, and their impacts on soil and water quality will likely exacerbate the effects of climate change by further degrading other ecosystems, such as Coral reefs and rivers, decreasing the land's ability to produce food (Uddin et al., 2017). It is much easier for farmers in developed countries to endure a climatic set back than those in poorer nations, where $80 \%$ of the popular lives in rural areas and approximately $40 \%$ of the economy is supported by rain agriculture (united Nation population Division, 2006). For example, as grazing areas dry up in subsheep, and wild life dependent on access to grazing areas for food will suffer. This will lead to greater conflict between people and animals (Menin, 2007).

The Links between Animal Production and Climate Change - The links between animal production and climate change are complex and multi-directional (Walter et al., 2010) can be viewed in terms of: (i) Contribution of animal production to climate change and (ii) impact of climate change on livestock production.

\section{Contribution of animal production to climate} change - According to IPCC (2007) report, the agriculture sector contributed between $10 \%$ and $12 \%$ of global emission of GHG, in terms of carbon dioxide equivalent. It contributed $40 \%$ of the total of anthropic emissions of methane (from enteric fermentation, decomposition of manure flooded rice fields) and $65 \%$ of the total of anthropic nitrous oxide (agricultural land use of nitrogenous fertilizers, spreading manure and burning biomass). In the mentioned 2006 report, applying life cycle analysis methodologies, FAO calculated that $18 \%$ of total emission of GHG were attributable, directly or indirectly contribution from the use of the land for livestock production (mainly deforestation to create pasture and arable land)
(Steinfeld et al., 2006 ). As to the report by OECD, livestock production is seen as being more intensive in terms of emission than other forms of food production or particular concern on the impact of changes in the use of land. The demand for arable land for crop production and pasture land has been the main driver of deforestation in certain developing countries. But at the same time, livestock production is vital for millions of people as the source of food, the generation cobenefits and a source of income.

Impact of climate change on livestock production - In IPCC Third Assessment Report (2007), there was a section devoted that the vulnerability of animal production, warming those animal production facilities will be affected both directly and indirectly by climate change. The direct effects include the interchange of heat between the animal and its environment, associated with temperature, humidity, wind spread and thermal production. These are factors that influence animal performance (growth, milk and wool production, reproduction), as well as animal health and welfare. The indirect effects include the influence of climate on the quantity and quality of fodder crops and grains, and severity and distribution of diseases and parasites (Islam et al., 2020). When the magnitudes (intensity and duration) of adverse climate conditions exceed certain limits, with little or no possibility of recovery, animal functions are adversely affected as a result of stress, at least in the short term. Genetic variation, the stage in the life cycle and nutritional status also influence their vulnerability and resilience to environmental stress. For example milk production from dairy cattle and conception rates can fall dramatically, and vulnerable animals may die as a result of extreme events (IPCC, 2007).

Links among Climate Change, Animal Production and Diseases - Climate change influences local weather conditions and therefore has significant impacts on the presence of insects and their geographical distribution and has had an unprecedented worldwide impact on emerging and re-emerging animal diseases and zoonoses (IAEA, 2017); resulting in negative effects on livestock health in many aspects (Nejash and Kula, 2016). Not only climate change, the production system of animals may also have negative impacts on animal 
diseases. For example, intensifying production systems will increase the opportunity for emerging and reemerging animal diseases and management systems need to be developed to minimize their direct and indirect effects on production and profitability. This means that in response to actual or anticipated emerging and re-emerging animal diseases, animal production systems will be adjusted or re-developed (Fig 3). The relationship is in fact a continuous interplay in which changes in one element of the complex system lead to changes in other parts of a system (Nunn and Black, 2006).

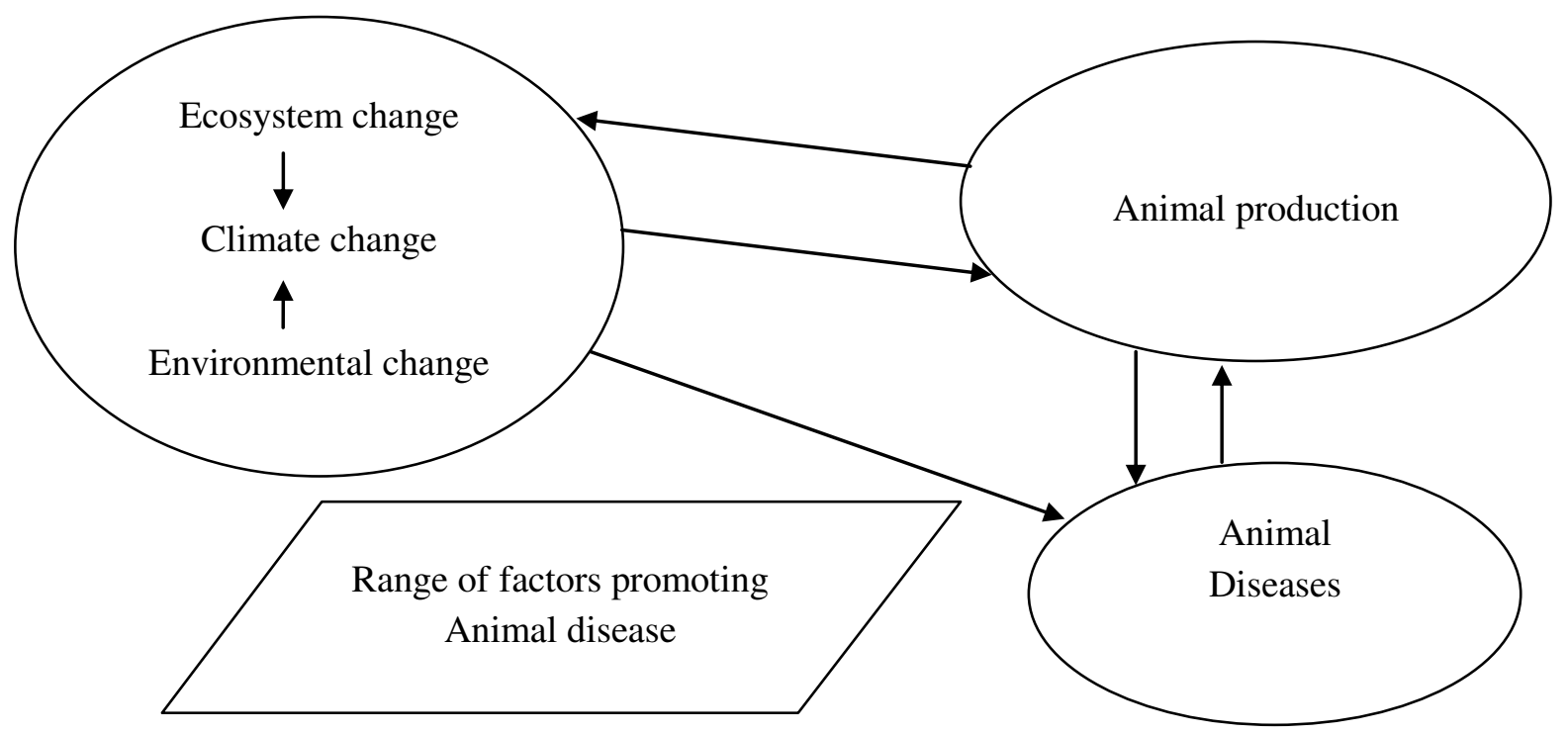

Fig 3: Relationship between animal diseases, climatic change, environmental change and animal production

(Nunn and black, 2006).

\section{CONCLUSION AND RECOMMENDATIONS}

The world's climate is changing at a faster rate. Even though changes in climate and extreme weather events have received increased attention in the recent years; climate change is real and is happening now with concomitant changes in precipitation, flooding, winds and frequency of extreme events such as El Nino. The average temperature in the world has increased in the last few years compared to the previous century and is expected to continue rising. Climate change can have direct and indirect effects on infectious diseases through disrupting natural ecosystems and providing more suitable environments for infectious diseases allowing disease-causing bacteria, viruses, and fungi to move into new areas where they may harm wild life and domestic species, as well as humans and it is exacerbating diseases in livestock. The distribution and incidence of vector borne diseases are directly influenced by climate since the geographical distributions of vectors are pre-determined by temperature and humidity. Animal production and climate change are inter-linked in complex and multiUniversePG I www.universepg.com directional ways; i.e. animal production systems can be sources of climate change through releasing gases and deforestation for production of animal feed; while, climate change affects animal production through desertification, water scarcity, changes in feed (availability, access, and appropriateness) etc. But, both the change in climate and production systems of animals have impacts on diseases of animals; as a result, leading to low productivity of animals, the impact being devastating in developing countries. This suggests that climate change, animal production and animal diseases are closely related and influence each other through different mechanisms.

Based on the current review, the following recommendations are forwarded:

Awareness creation, in working in an integrated systematic manner, should be made to the stakeholders in the environmental conservation, animal production and animal health. 
Sustainable animal farming and land use, and climate adaptation and mitigation strategies should be developed.

$>$ Researches with emphasis given to the state of climate change and the direct and indirect effects it pose on animal production and on the occurrence and distribution of animal diseases' should be conducted.

\section{ACKNOWLEDGEMENT}

We thank the previous authors for their contribution regarding this field of study.

\section{COFLICTS OF INTEREST}

No conflict of interest was reported by the author.

\section{REFERENCES}

1) Abrar A, Beyene T, and Furgasa W. (2020). Isolation, identification and antimicrobial resistance profiles of Salmonella from dairy farms in Adama and Modjo Towns, Central Ethiopia. Eur. J. Med. Health Sci, 2(1), 1-11. https://doi.org/10.34104/ejmhs.02001011

2) Abedin MZ, Ahmed AA, and Aktar MB. (2020). Laboratory based diagnosis of bacteraemia among inpatients and outpatients with acute febrile illness at Khwaja Yunus Ali Medical College and Hospital in Bangladesh. Eur. J. Med. Health Sci., 2(3), 46-51. https://doi.org/10.34104/ejmhs.020.046051

3) Baylis M., and Githeko, A. K. (2006). The effects of climatic change on infectious diseases of animals. In Infectious diseases: preparing for the future. Office of Science and Innovation, United Kingdom, Pp, 35.

4) Bett B. Kiunga, P., T., Lindahl, J. and Grace, D. (2016). Effects of climate change on the occurrence and distribution of livestock diseases; Elsevier B.V.; Preventive Veterinary Medicine; 137, 119-129.

5) Bosh I., Herrera, E., Dupuis, A., Maffei, J. and Kramer, L. (2007). West Nile virus, Venezuela emerg. Infect. Dis., 13: 651-653.

6) Cardenas R., Sandoval, C. M., A.J., and Franco- paredes, C. (2006). Impact of climate variability in the occurrence of Leishmaniosis in Northeaster Colombia. Am. J. trop. Med Hyg. 75 : 273-277.

https://doi.org/10.4269/ajtmh.2006.75.273

7) Daszak P., Cunningham, A., and Hyatt, A.D. (2003). Infectious disease and amphibian population decline. J. Divers. Distrib., 9: 141150.

8) De La Rocque, S. (2008). Introduction In Climate Change: impact on the epidemiology and control of animal diseases. Rev. sci. tech. Off. int. Epiz., 27: 303-304.

9) Epstein P.R. and Mills, E. (2005). Climate Change Futures: Health, ecological and economic Dimensions. Harvard Medical School.

10) Gatewood A.G., Liebman, K.A., and Diukwaser, M.A. (2009). Climate and tick seasonality are predictors of Borrelia burgdorferi genotype distribution. Applied and Environment. Microbiol., 75: 2476-2483. https://doi.org/10.1128/AEM.02633-08

11) Gibbens N. (2008). Schmallenberg virus: a novel viral disease in northern Europe. Veterinary Record. Pp. 170.

12) Gloster J., Burgin, L., Mets, F. R., \& Mellor, Y. S. (2008). Bluetongue in the United Kingdom and Northern Europe in 2007 and Key Issues for 2008, Vet Rec. 162(10): 298302. https://doi.org/10.1136/vr.162.10.298

13) Hansen J. L., Hanter., Nazarenko, R., Ruedy, M., and Tausney, N. (2005). Earth's energy imbalance confirmation and implications. Science, 308: 1431-1435.

14) Hasle G. Bjune. G. Edvardsen, and Leinaas, H. P. (2009). Transport of ticks by migratory passerine birds to Norway: J. parasitology, 95: 1342-1351.

15) Helene G., Cyril C., Annelise T. and Matthew B. (2011). Modelling the effects of past and future climate on the risk of bluetongue emergence in Europe. J R Soc Interface, 9(67): 339-50. https://doi.org/10.1098/rsif.2011.0255

16) International Atomic Energy Agency (IAEA 2017). Climate Change and the Expansion of Animal and Zoonotic Diseases - What is the Agency's Contribution? Nuclear techniques in food and agriculture; joint FAO/IAEA program 2003-2017. 
17) Intergovernmental panel on climate change (IPCC), 2007. Impacts, adaptation and vulnerability. Contribution of working group II to the Fourth Assessment Report of the Intergovernmental panel on climate change. Cambridge University press, Cambridge.

18) Islam MJ, Sarker TC, Jebin RA, Yasmin F, and Uddin MKM. (2020). Determination of optimum survivability factors of highly pathogenic Vibrio cholerae 01 serogroup specific bacteriophage JSF4 $\phi$. American J. of Pure and Applied Biosciences, 2(2), 8-14. https://doi.org/10.34104/ajpab.020.08014

19) Jonzen N.,Linden, A., E.,Solvanng, R., and Stenseth, N. C. (2006). Rapid advance of spring arrival dates in long-distance migratory birds. Science, 312: 1959-1961.

20) Kimaro E. G. and Chibinga, O. C. (2013). Potential impact of climate change on livestock production and health in East Africa: A review; Livestock Research for Rural Development, 25(7): 1-11.

21) Kleiboeker S.B., and Scoles, G.A. (2001). Pathogenesis of African swine fever virus in Ornithodoros ticks. Animal Health Research Reviews, 2: 121-128.

22) Kutz S.J., Hoberd, E.P., Polley, L., and Jenkins, E.J. (2005). Global warming is changing the dynamics of Arctic host- parasite systems proceedings of the Royal Society, 272: 2571-2576.

23) Lehikoinen E., Sparks, T.H., and Zalakevicius, M. (2004). Arrival dates and departure times. Adev. in Ecologic. Research, 35: 1-28.

24) Lenarz M.S., Nelson, M.E., Seharge. M.W., and Edwards, A.J. (2009). Temperature mediated moose survival in northeastern Minnesota. J. wildlife manag., 73: 503-510. https://doi.org/10.2193/2008-265

25) Li W., shi, Z., Yu, M., and Wang, L. 2005. Bats are natural reservoirs of SARS- like Corona virus. Science, 310: 67-679.

26) Lindgren E., Talleklint., I., and polfeldt. T. (2000), Impact of climate change on the northern latitude limit and population density of the disease transmitting Europena tick
Idoides ricinus. Environmental Health perspectives, 108: 119-1247.

27) Lowen A.C., Mubareka, S., Steel, J and Palese P. (2007). Influenza virus transmission is dependent on relative humidity and temperature. PLoS. Pathog. 3:151. https://doi.org/10.1371/journal.ppat.0030151

28) Madeira N. G., Amarante, A. F. T., and Padovani, C. R. (2005). Effect of management practices on screw worm among sheep in Sao Paulo State. Brazil. Trop. anim. Ppor. 30. 149-157.

29) Md. Ekhlas Uddin, Pulak Maitra, Hossain Md. Faruquee, Md. Firoz Alam, (2014). Isolation and characterization of proteases enzyme from locally isolated Bacillus sp., American J. of Life Sciences. 2(6), 338-344. https://doi.org/10.11648/j.ajls.20140206.12

30) Menin R. (2007). Human Development Report 2007/2008. Fighting climate change: Human solidarity in a divided world. Famine in Malawi: Causes and consequences. United Nations Development Program.

31) Murray D. L., Cox, E. W., and Fuller, T, K. (2009). Pathogens, nutritional deficiency and Climate influences on a declining moose population. Wildlife Mono-graphs, 166: 1-30.

32) Nas FS, Yahaya A, Muazu L, Halliru SN, and Ali M. (2020). Prevalence of Trichomonas vaginalis among pregnant women attending ante-natal care in Kano, Nigeria. Eur. J. Med. Health Sci., 2(2), 39-45.

https://doi.org/10.34104/ejmhs.020.39045

33) Nejash Abdela and Kula Jilo, (2016). Impact of Climate Change on Livestock Health: A Review; IDOSI Publications; Global Veterinaria; 16(5): 419-424.

34) Nunn M., and Black, P. (2006). Intensive animal production systems: How intensive is intensive enough? Eleventh Symposium of the International Society for Veterinary Epidemiology and Economics, Cairns, Australia.

35) Purse B.V., Mellor, P.S., A.R., Mertens, p.p., and Baylis, M. (2005). Climate change and the recent emergence of bluetongue in Europe. Nature Rev. Microbiol. 3: 17-181. https://doi.org/10.1038/nrmicro1090 
36) Rafiquzzaman SM. (2020). Case Study on the Impact of Pandemic COVID-19 in Aquaculture with its Recommendations. Am. J. Pure Appl. Sci., 2(2), 36-38. https://doi.org/10.34104/ajpab.020.36038

37) Rahman MA, Ahmad T, Mahmud S, Uddin ME, and Ahmed R. (2019). Isolation, identification and antibiotic sensitivity pattern of Salmonella spp. from locally isolated egg samples, Am. J. Pure Appl. Sci., 1(1), 1-11. https://doi.org/10.34104/ajpab.019.019111

38) Randolph S. E. (2009). Tick- borne disease systems emerge from the shadows: The beauty lies in molecular detail, the message in epidemiology parasitology, 136: 1403-1413.

39) Rappole J.H., Derrickson, S.R., Raiter, and Hubalek, Z. (2000). Migratory birds and spread of West Nile virus in the Western Hemisphere. Emerg. Infect. Dis., 6: 319-328.

40) Reed K.D., Meece, J.K., Henkel, J.S., and Shukla, S.K. (2003). Bird's migration and emerging zoonoses West Nile virus, Lyme disease, Influenza A and enteropathoges. Clin Med Res., 6: 5-12.

https://doi.org/10.3121/cmr.1.1.5

41) Relman D.A., Hamburg, M.A., and Mack, A. (2008). Forum on Microbial Threats of the Institute of Medicine. Global Climate Change and Extreme Weather Events: Understanding to Infectious Disease Emergence.

42) Saino N., Ambrosini, R., Rubolini, D., and Sokolov, L. (2011). Climate warming ecologic mismatch at arrival and population decline in migratory birds' proceedings of the Royal Society, 278: 835- 842.

43) Sarkar C, Jamaddar S, Zulfiquar TN, and Mondal M. (2020). Boon and Bane of Transgenic Animal: A Brief Review. Eur. J. Med. Health Sci., 2(2), 21-27. https://doi.org/10.34104/ejmhs.020.21027
44) Shahen MZ, Mahmud S, Rony MH, Al Maruf MA, Uddin ME and Alam MS. (2019). Effect of antibiotic susceptibility and inhibitory activity for the control of growth and survival of microorganisms of extracts of Calendula officinalis, Eur. J. Med. Health Sci. 1(1), 1-9. https://doi.org/10.34104/ejmhs.019

45) Siddig A., Al Jowary, S., Hopkins M.J.R., and Slingenbergh, J. (2005). Seasonality of Old World screwworm myiasis in the Mesopotamia valley in Iraq. Medical and Veterinary Entomology, 19: 140-150.

46) Smeraldi M., \& May, P., 2008. The Cattle Realm: A new phase in the livestock colonization of the Brazilian Amazonia.

47) Steinfeld H., Gerber, P., Rosales, M. \& de Haan, C. (2006). Livestock's long shadow: environmental issues and options. Food and Agriculture Organisation, Rome.

48) Thorup k., Tottrup, A.p., \& Rahbek, C. (2007). Patterns of phonological changes in migratory birds ecologia, 131: 697-703.

49) Uddin M. E., Ahmad T., Ray S. K., and Ahammed T. (2017). Thermotolerant extracellular proteases produced by Bacillus subtilis isolated from local soil that representting industrial application. J. of Pure and Applied Microbiol. 11(2), 733-741. https://doi.org/10.22207/JPAM.11.2.12

50) Walter O., Edgardo V. and Patricia. (2010). Climate Change and Links to Animal Diseases and Animal Production; Ministry of Livestock, Agriculture and Fisheries of Uruguay; Conf. OIE, 179-186.

51) Zhang G., Shoham, D., Gilichinsky, D., Davydov, S., Castello, J.D. and Rogers, S.O. (2006). Evidence of Influenza A virus RNA in Siberian Lake ice. J. Virol, 24: 12229-12235. https://doi.org/10.1128/JVI.00986-06

Citation: Haile WA. (2020). Impact of climate change on animal production and expansion of animal disease: a review on Ethiopia perspective. Am. J. Pure Appl. Sci., 2(3), 64-76. https://doi.org/10.34104/ajpab.020.064076 (C) () 